\title{
The Aging Effects of Aluminum Magnesium Alloy Welding Wires
}

\section{The properties of welding wires from different manufacturers under various storage conditions were compared}

\author{
U. REISGEN, K. WILLMS, AND S. WIELAND
}

\begin{abstract}
The properties of aluminum magnesium welding wires Al 5183 from three different manufacturers were compared during a storage period of seven weeks in a constantly humid and warm climate. The change in winding diameter, vaporable containment, adhesion factor, and hydrogen content were investigated. Changes in electric characteristics during the gas metal arc welding process in the overhead position, and the resulting amount of pores in the weld metal, were also investigated. Furthermore, examination methods were used to analyze welding wires of one manufacturer during a storage period of almost ten months in an indoor climate and in a constantly humid and warm climate. It was found that substance changes on the welding wire surfaces had a greater effect on the welding wire properties, such as the hydrogen quantity, and the welding process characteristics, such as power and depth of fusion, than the growth of the natural oxide layer. No significant pores due to hydrogen on the welding wire surfaces were found in the weld metal.
\end{abstract}

\section{KEYWORDS}

- Aluminum Magnesium Welding Wire • Hydrogen Quantity

- Vaporable Containment • Winding Diameter • Adhesion Factor

- Natural Aluminum Oxide Layer • Antifriction Agent

\section{Introduction}

In our recently published investigation dealing with aluminum silicon alloy welding wires (Ref. 1), it was found that considerable pore formation in the weld metal can only form due to the effect of condensation climates on the welding wire surfaces. Furthermore, the welding wire properties vary in their dependence of the alignment and position of a specific wire section on the spool.

In this research, aluminum magnesium welding wires Al 5183 were examined to clarify the influence of magnesium as an important alloying element to the aging of aluminum welding wires. Manufacturers of aluminum welding wires apply antifriction agents of different compositions to the wire surfaces that are kept secret. On the one hand, these substances may affect the total hydrogen quantity of the welding wires. On the other hand, they are also suspected to influence the growth of the natural oxide layer (Ref. 2). Therefore, assuming an identical aluminum alloy composition as well as similar geometrical and mechanical properties, one of the most significant differences between welding wires from different manufacturers is the amount and composition of the antifriction agent.

Generally, the production of aluminum weld metal without the formation of pores is a challenge (Ref. 3). The pores are reported to form by hydrogen only (Refs. 3-6). During the solidification of aluminum weld beads, the solubility of hydrogen leaps by one order of magnitude (Ref. 7). The pores can be trapped within the weld metal if they are hindered from welling up or degassing by fast solidification, especially during out-of-position welding (Ref. 3). In addition to the base material and shielding gas, aluminum welding wires can provide hydrogen to the welding process. Hydrogen gradually intercalates into the surface layer of the natural oxide layer on the aluminum filler material (Refs. 3, 5, 8-11).

There are general recommendations for maximum storage durations available (Refs. 3, 9, 11). However, there are only a few quantitative details recorded, making these recommendations hard to comprehend. Moreover, the effect of antifriction agents was not taken into account either on the total hydrogen quantity or on the natural oxide layer growth. The natural oxide layer builds up instantaneously under the influence of ambient air on aluminum surfaces (Refs. 2, 12). The oxide layer can be distinguished into an insulating barrier layer and a surface layer, which absorbs hydrogen in moist ambient air (Ref. 13). The total thickness of the oxide layer in indoor air remains within a range of $12 \mathrm{~nm}$ (4.73E-7 in.) even after months of storage (Ref. 14) because of the selfinhibition of the growing process. Accordingly, the total hydrogen content on aluminum surfaces must also remain within a threshold value, since the surface layer can absorb hydrogen only by growing in thickness, whereas its composition remains the same.

Figure 1 depicts the formation of a natural aluminum oxide layer due to the influence of dry or moist environmental air. Heterogeneities in the ma- 


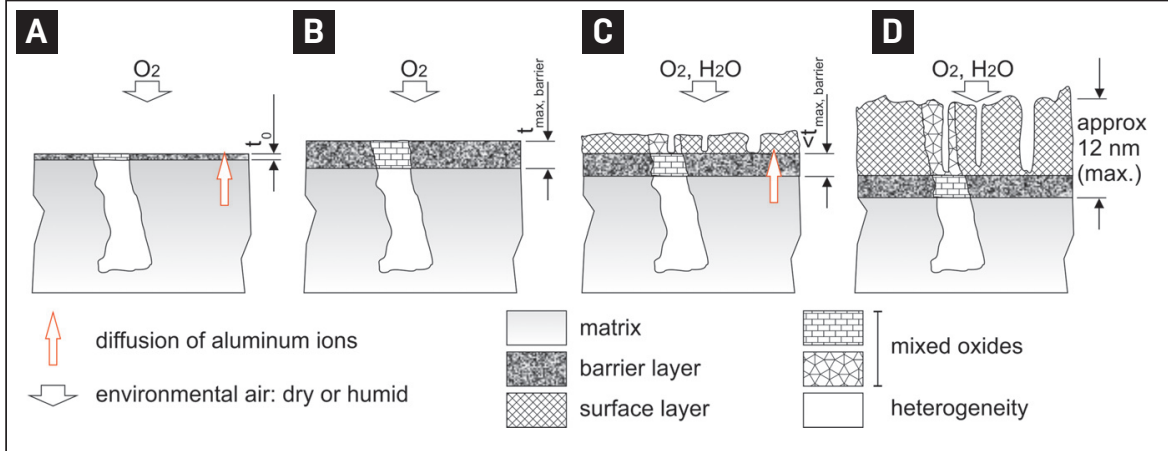

Fig. 1 - Formation of a natural oxide layer on aluminum due to environmental air influence: A - Instantaneous thin barrier layer; B - self inhibition in dry air at maximum barrier layer thickness; $C$ - growth of surface layer in moist air; $D-$ self inhibition at maximum total oxide layer thickness in moist room air.

Table 1 - Definition of the Test Climates

$\begin{array}{cc}23 \pm 3 & 33 \pm 10 \\ 30 & 93\end{array}$

trix, such as intercalations and alloying elements, influence the composition of the oxide layer, resulting in mixed oxides. Aside from what is depicted in this schematic representation, the heterogeneities have a much greater diameter than the thickness of the oxide layer (Ref. 14).

Generally, the corrosion resistance of aluminum increases with the continuity of the oxide layer, or rather with the purity of aluminum (Ref. 12). The growth of the oxide layer can be hindered by alloying elements that accumulate at the grain boundaries, hindering the aluminum ions from further diffusion through the oxide layer (Ref. 15). However, the corrosion resistance has to be distinguished from the oxide layer thickness. A thin oxide layer can be sufficient to prevent further corrosion. Thus, magnesium, as an alloying element in certain content ranges, does not necessarily lead to a decreasing corrosion resistance in comparison to other aluminum alloys (Ref. 16). On the contrary, if the natu- ral oxide layer on the aluminum magnesium alloy is thinner, the intercalated hydrogen quantity could be less.

Magnesium also influences the mechanical properties of the welding wires, especially the winding diameter and its change during storage. Thus, the effects of aging during storage on the power transmission in the contact tip and the friction in the wire guidance core are expected to show a significant difference.

\section{Experimental Procedures}

\section{Climates}

Two different storage conditions were defined in Table 1 . The indoor (ind.) climate was put into effect by storing the welding wires in the machine hall of the Welding and Joining Institute in Aachen, Germany, where a weather station recorded the climate during the storage period. The wires were unpacked and put back into their paperboard container to protect them from dispersible dust. The plastic bags were discarded.

A climate cabinet with forced ventilation was used to store a second group of welding wires in a constant humid and warm (h.w.) climate that may occur in practice. These wires were stored without any packaging. An acceleration of corrosion processes by a further increased temperature may cause a poor comparability of test results since corrosion processes take place discontinuously (Ref. 14).

\section{Filler Material}

Solid wires EN ISO 18273-S Al 5183A (AlMg4.5Mn0.7) (Ref. 17) with a diameter of $1.2 \mathrm{~mm}$ (4.7E-2 in.) were used. The chemical compositions according to the EN ISO 18273 and AWS/ASTM A5.10 ER5183 standards (Welding Consumables - Wire Electrodes, Wires and Rods for Welding of Aluminum and Aluminum Alloys - Classification) are opposed to each other (Table 2). For each manufacturer, all of the welding wires originated from the same batch, coiled on spools with an outer diameter of $300 \mathrm{~mm}$ (11.8 in.). Sufficient spools were stored to permit each test to be performed on the topmost winding level of the welding wire after aging for a specific period of time. Unless otherwise noted, the results presented in this work refer to this winding level, since the ambient atmosphere took effect on these surfaces directly, whereas the winding levels underneath were sheltered (Ref. 1).

\section{Different Manufacturers}

A comparison of the change of welding wire properties during the first seven weeks of storage was executed with welding wires from three different nameable manufacturers ( 1 , 2 , and 3) in a h.w. climate. The welding wires originated within the United States and Europe.

Table 2 - Chemical Composition of 5183A Welding Wire According to EN ISO and AWS/ASTM Standards

\begin{tabular}{lccccccccc} 
& $\mathrm{Si}$ & $\mathrm{Fe}$ & $\mathrm{Cu}$ & $\mathrm{Mn}$ & $\mathrm{Mg}$ & $\mathrm{Cr}$ & $\mathrm{Zn}$ & $\mathrm{Ti}$ & $\mathrm{Al}$ \\
\hline EN ISO 18273 - S Al 5183A & 0.40 & 0.40 & 0.10 & $0.4-1.0$ & $4.0-4.9$ & $0.05-0.25$ & 0.25 & 0.15 & Rest \\
AWS/ASTM A5.10 ER5183 & 0.40 & 0.40 & 0.10 & $0.5-1.0$ & $4.3-5.2$ & $0.05-0.25$ & 0.25 & 0.15 & Rest \\
\hline
\end{tabular}

*Single values are maximum values. 


\section{Long-Term Investigation}

During a period of ten months, the effect of storage in ind. and h.w. climates on the change of welding wire properties, the welding process, and the weld metal was investigated with wires from a single manufacturer (manufacturer 1) only.

\section{Winding Diameter}

In this research, the diameter of a loose welding wire winding laid on a flat plane was referred to as "winding diameter."

\section{Smoke Test}

Substances clinging to the welding wire surfaces cannot be characterized with any measuring method directly. However, vaporable containments from substances - such as residues from drawing agents and the previously mentioned antifriction agent clinging to the welding wire surfaces - can be detected with smoke tests. These tests are not standardized, and the resulting values ("sum of smoke") depend on the detector of the measurement device and each manufacturers' composition of the substances. Therefore, the results may not be compared quantitatively with one another. In this research, a MIG WELD SMKY 510 residual analyzer was used with a current impulse of $302 \mathrm{~A}$ for 302 $\mathrm{ms}$. Each measured welding wire section had a length of approximately $250 \mathrm{~mm}$ (9.8 in.).

\section{Adhesion Factor}

The adhesion factor $\mu$ between a welding wire and a polytetrafluoroethylene (PTFE) wire guidance core that has an inner diameter of $2.0 \mathrm{~mm}$ (7.9E-2 in.) was determined using a force ratio by means of the EulerEytelwein formula - Equation 1.

$$
\mu=\ln \frac{F_{P}}{F_{L}} * \frac{1}{\alpha}
$$

For this purpose, a nonstandardized test bench was designed - Fig. 2 . A PTFE wire guidance core was coiled in a defined angle $\alpha$ of $3 \pi$ around a cylinder with a radius of $250 \mathrm{~mm}$ (9.8 in.). A welding wire section of approxi-

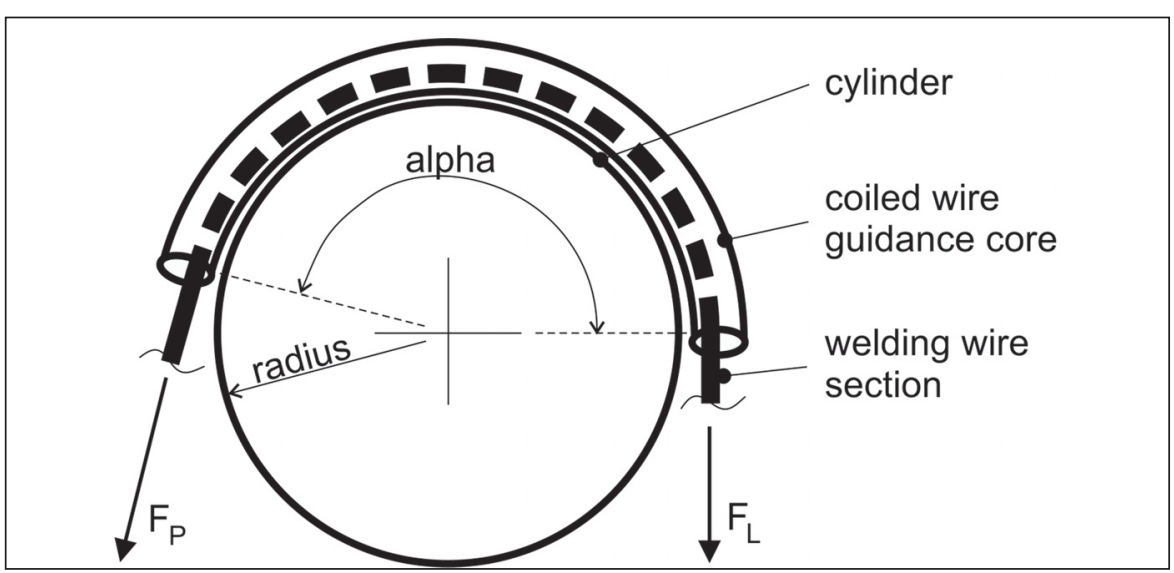

Fig. 2 - Graphic account of the test bench for determining the adhesion factor.

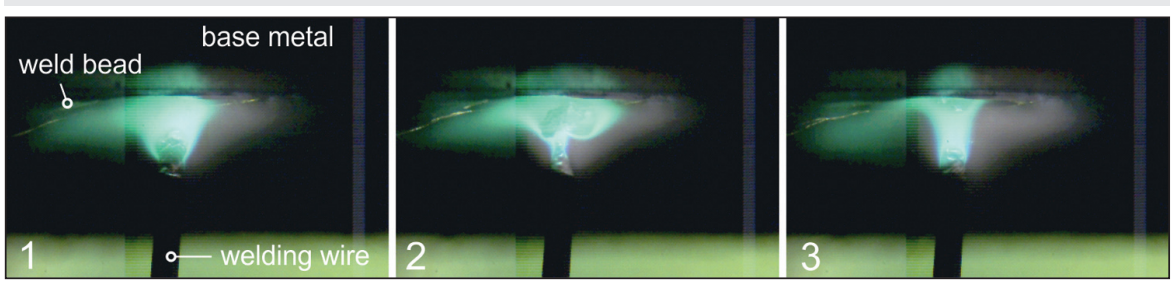

Fig. 3 - Droplet detachment in the overhead welding position with a globular transfer (new welding wire, manufacturer 1).

Table 3 - Gas Metal Arc Welding Parameters

\begin{tabular}{ccc} 
Parameter & Unit & Value \\
\hline Welding position & & Overhead \\
Welding speed & $\mathrm{m} / \mathrm{min}$ (in./min) & $1.15(45.3)$ \\
Wire feed speed & $\mathrm{m} / \mathrm{min}$ (in./min) & $12.5(492)$ \\
Shielding gas flow & $\mathrm{L} / \mathrm{min}$ & 18 \\
Contact tip distance & $\mathrm{mm}$ (in.) & $14(0.55)$ \\
Mean process voltage & $\mathrm{V}$ & 21.5 \\
Electrode polarity & & DCEP \\
Weld bead length & $\mathrm{mm}$ (in.) & $200(7.87)$ \\
Weld bead type & & Stringer bead
\end{tabular}

mately $2.4 \mathrm{~m}$ (94.5 in.) in length was contrived and charged with a defined load on one end $\left(\mathrm{F}_{\mathrm{L}}\right)$. The other end was connected to a load cell. It was pulled until the measured force $\left(\mathrm{F}_{\mathrm{p}}\right)$ corresponded to the transition from static to dynamic friction. $\mu$ is a comparative value in the context of the investigation at hand, not an absolute value for practice since the influence of a contact tip could not be included in this method. To suppress the influence of abrasion from the welding wire surfaces, the core was replaced after each measurement.

\section{Hydrogen Quantity}

The hydrogen quantity of the welding wires was determined using the inert gas fusion (IGF) method according to a proceeding described in Ref. 18. A Bruker G8 Galileo ON-H analyzer was used. Each data point was composed of the arithmetic mean of three measurements. Each measurement generated a single hydrogen value that represented the sum of all various hydrogen sources of the welding wire at once, such as the surface layer, residues from the drawing agent, antifriction 

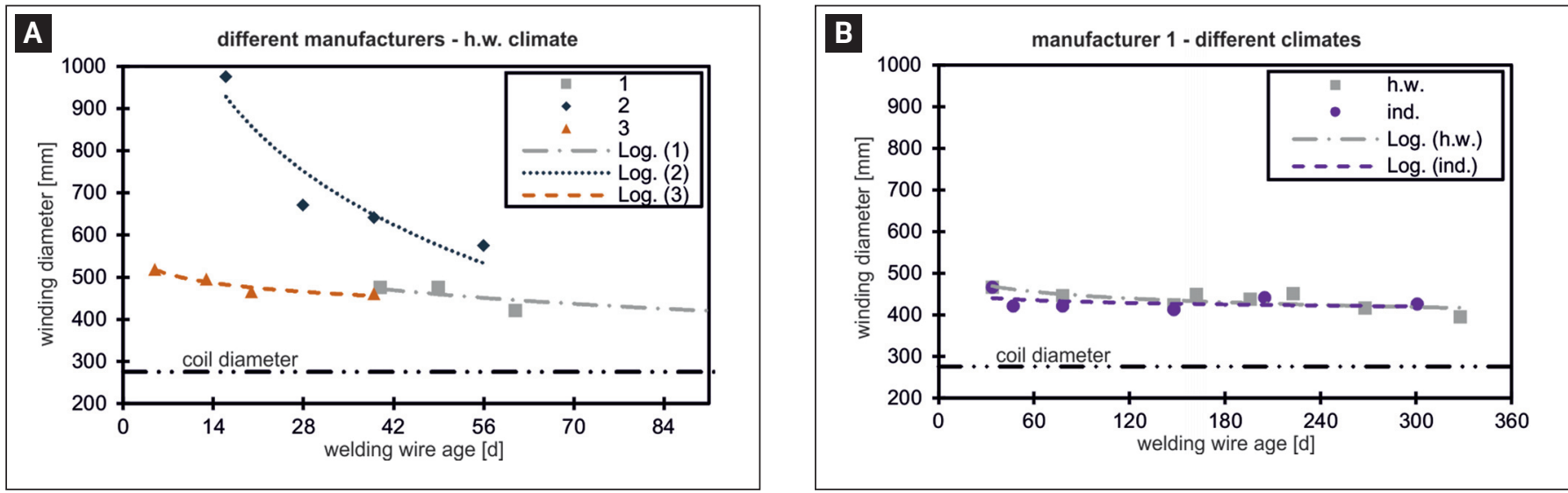

Fig. 4-Winding diameter of the welding wires.
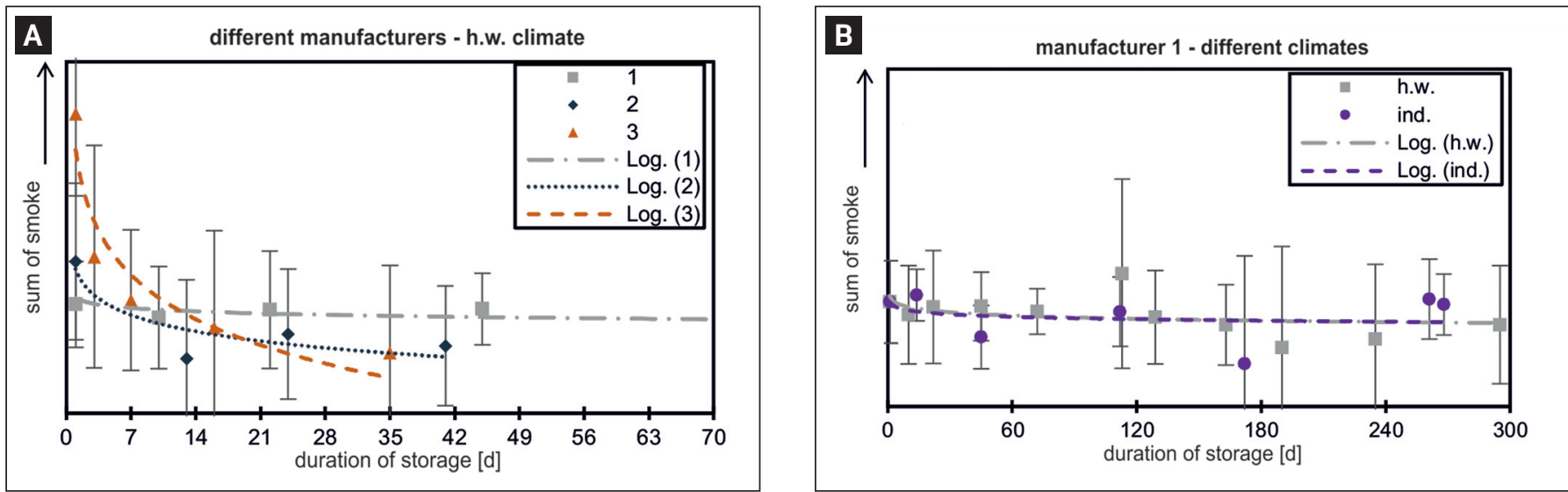

Fig. 5-Sum of smoke (qualitative only).

agent, and inside the welding wire bulk material. The latter can be considered constant for each batch. Variations in the measured values resulted from surface effects only.

\section{Welding Process and Its Electric Characteristics}

The change of welding process characteristics due to the welding wire state was examined by producing surfacing welds in a fully mechanized welding process. When welding in an overhead position, occurring pores are trapped at the weld interface when welling up (Refs. 1, 3). Etched AlMg4.5Mn plates of $250 \times 100 \times 5$ $\mathrm{mm}^{3}\left(9.8 \times 3.9 \times 0.2\right.$ in. $\left.^{3}\right)$ were used as the base material. The plates were clamped on a water-cooled copper block to increase the cooling rate of the weld metal and freeze the emerging pores. A standard GMAW power source, EWM Phoenix 330 ColdArc, with a push-pull wire feeder and a conventional constant voltage synergic power characteristic was used. An argon shielding gas of purity $\geq 99.996 \%$ was chosen. To suppress other sources of hydrogen than the filler material, extensive actions were taken including the following:

- Flushing of the gas hose with shielding gas for $15 \mathrm{~min}$ at five $\mathrm{L} / \mathrm{min}$ gas flow after longer pauses.

- Frequent replacement of wearing parts in mechanical contact to the welding wire.

- Cleaning of the welding wire transport rolls with alcohol.

- Handling of all related parts and welding wires with clean latex gloves.

The welding parameters are recapped in Table 3. A stable spray arc of low power was derived, whereas a stochastic droplet detachment as a globular transfer developed - Fig. 3. During the welding process, the current and the voltage were measured by a digital scope with a sampling rate of $20 \mathrm{kHz}$. The voltage was measured between the contact tip and the workpiece, and the current was obtained using a hall sensor. Each data point represented an arithmetic mean of 10 $\mathrm{s}$ of transient measurement during steady-state welding.

\section{Results}

In Figs. $4 \mathrm{~A}$ to $6 \mathrm{~A}$ and Figs. $8 \mathrm{~A}$ to $9 \mathrm{~A}$, the changes in welding wire properties from three different manufacturers (1, 2, and 3) stored in a h.w. climate are comparatively depicted for the first seven weeks. In the B Figures, the long-term changes are depicted, respectively, for the welding wires from manufacturer 1 , stored either in ind. or h.w. climates. All time-inscriptions refer to the date in which the original packaging ("duration of storage") from the welding wires was removed, since it was expected that the property changes began from this moment. Only the change in the winding diameter (Fig. 4) was set into relation with the production date ("welding wire age") because relaxation took place from this moment onward. Loga- 

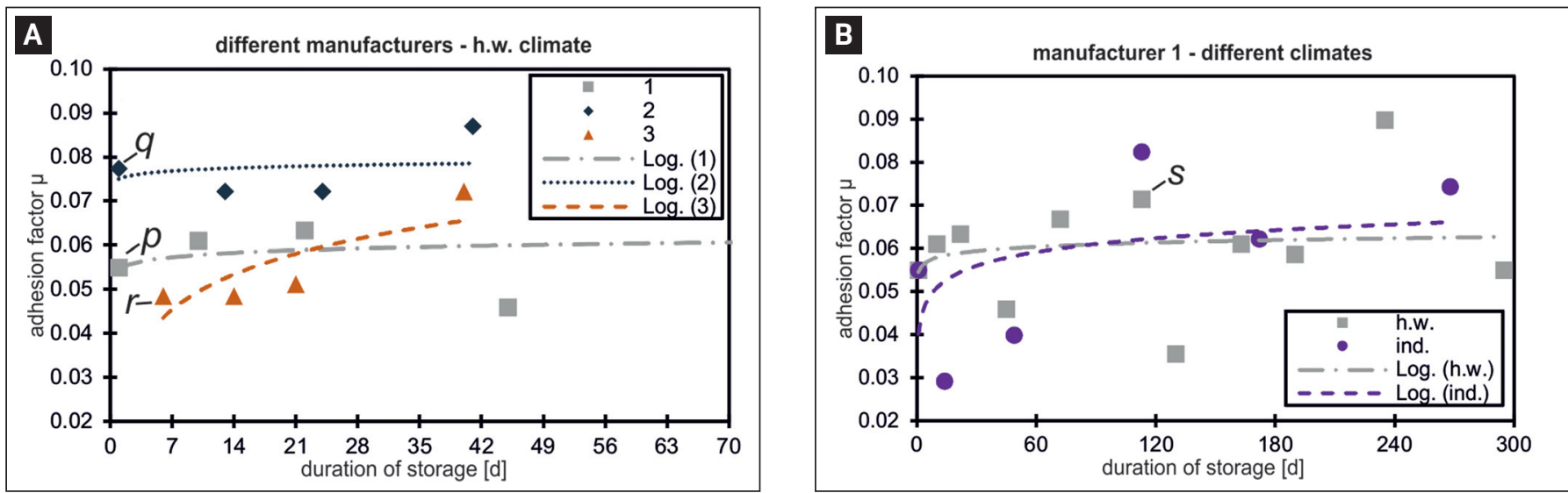

Fig. 6 - Adhesion factor $\mu$ between the welding wires and a PTFE wire-guidance core.

rithmic trend lines were used to visualize the changes because logarithmic laws are supposed to match the natural changes best and illustrate the convergence to threshold values.

Depending on the manufacturer, the shipping durations of welding wires varied. This resulted in different starting dates for the first measurement in relation to the welding wire age - Fig. 4A. The winding diameter can be set to different values by the manufacturer. A considerable decrease of the winding diameter became apparent for the welding wire of manufacturer 2, who supplied welding wire with the largest winding diameter.

Concerning the vaporable containment, represented by the sum of smoke depicted in Fig. 5, there was a basic ample standard deviation. However, trend lines revealed a decreasing sum of smoke in either case. The initial values of the sum of smoke differed with respect to the different manufacturers - Fig. 5A.

During the first days after opening the packaging, the sum of smoke decreased significantly. The higher the initial value, the more considerable the decrement (manufacturers 2 and 3 ). After approximately two weeks in a h.w. climate, the sum of smoke had decreased to a lower, time-invariant value. During long-term storage, no difference between the climates was distinguished - Fig. 5B.

Figure 6 depicts the adhesion factors derived from the welding wires of different manufacturers and during long-term storage. The measured values of this welding wire property exhibited a considerable deviation.

Figure 7 depicts the roughness val-

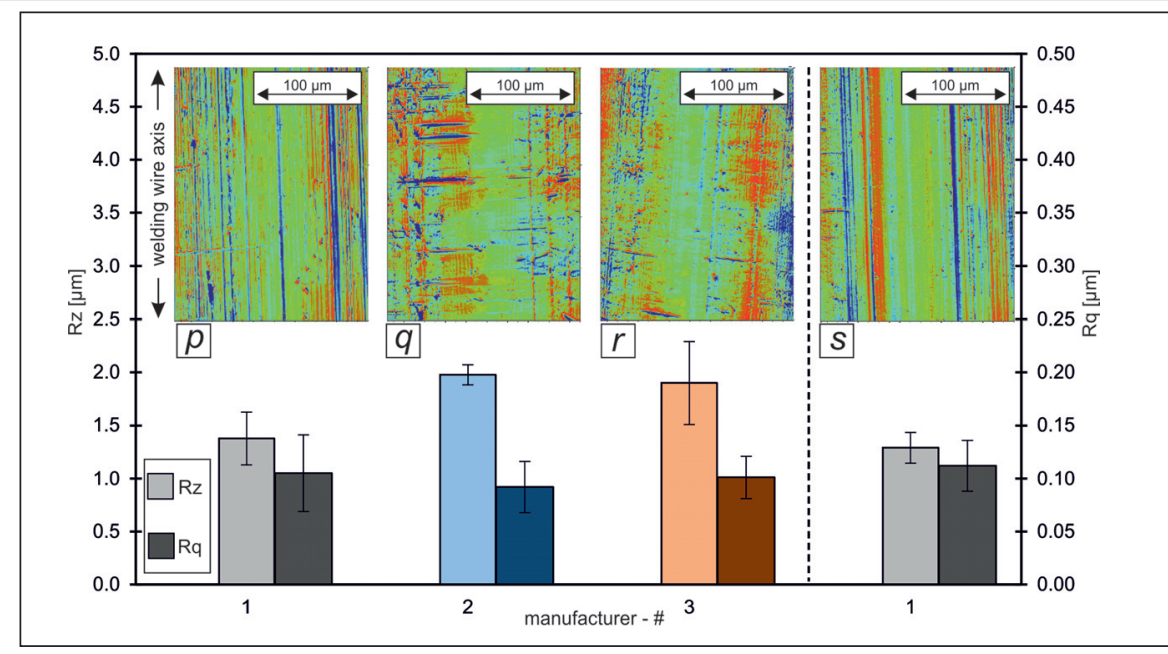

Fig. 7 - Statistical roughness values $R z$ and $R q$, the qualitative surface topography of the "new" welding wires ( $p, q$, and $r$ ), and a welding wire aged 112 days in a h.w. climate (s).

ues $\mathrm{Rz}$ and $\mathrm{Rq}$, which were each measured on three different areas $(245 \times$ $186 \mu \mathrm{m}^{2} / 9.6 \mathrm{E}-3 \times 7.3 \mathrm{E}-3$ in. $^{2}$ ) along the circumference of each welding wire due to the white light interferometry method. The surface topography is depicted qualitatively, whereas the curvature of the cylindrical welding wire surface is subtracted mathematically.

The measured hydrogen quantities, depicted in Fig. 8, consisted almost exclusively of adhesive hydrogen inside the natural aluminum oxide layer and the substances on the welding wire surfaces due to the manufacturing process. Against expectation, they decreased in either case.

Figure 9 depicts the resulting welding power of the welding process. All data hinted at an increase of welding power, resulting from an increase of welding current at constant voltage, using aged welding wires.
In the transient process voltage and current signals, major process disturbances were not identified, as can be seen in a representative extract of the transient welding process signals in Fig. 10.

Since the aging of a welding wire section coiled on a spool that takes place is dependent on the overlying winding levels (Ref. 1), the aging of different winding levels on the spool was investigated. Figure 11 shows the change of the process power using aged welding wires from different winding levels, and level 1 is the topmost level. The area of investigation was in the middle of the spool, more than ten windings away from the sidelong windings, to eliminate the influence of the climate intruding from there (compare to Fig. 13).

Figure 12 depicts two transverse cross sections and a longitudinal cross 

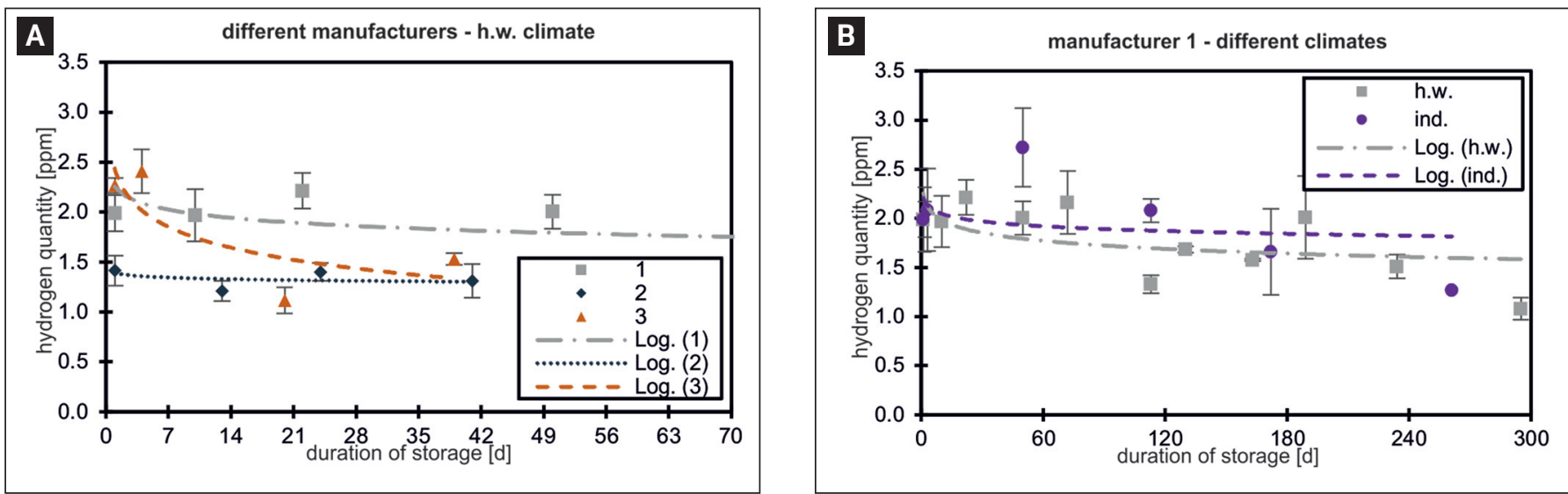

Fig. 8- Hydrogen quantity of the welding wires.
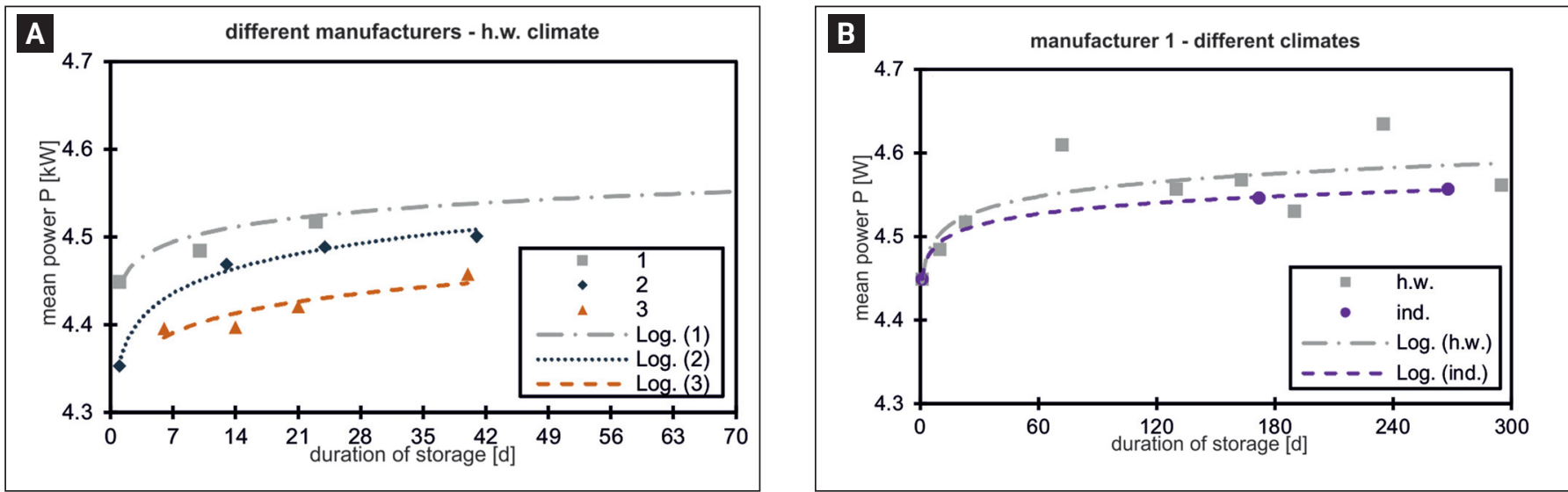

Fig. 9-Arithmetic mean welding power P.

section of the surfacing weld metal. Neither of the new welding wires from the three different manufacturers, nor the welding wires stored long term in a h.w. climate, caused pores. Since the process power increased from using aged welding wires, a growing depth of fusion came along with it. Pores were detected in an unwanted area of complete joint penetration.

\section{Discussion}

\section{Winding Diameter}

After long-term storage (Fig. 4), the winding diameter remained static at a value of approximately $150 \mathrm{~mm}(5.9$ in.) more than the diameter of the particular winding level coiled on the 300mm- (11.8-in.-) diameter spool. The different storage conditions did not significantly affect the decrease.

\section{Smoke Tests}

It may be concluded that the used measurement method is suitable for manufacturers to control their production since they have information about the influence of drawing and antifriction agents as well as their relation to one another to the sum of smoke. Supposing that a new welding wire represents the best quality, it could be assumed that any change in the sum of smoke hints to a deterioration.

However, the sum of smoke for manufacturer 1 remained nearly unchanged at any time, and its starting point was low - Fig. 5. Therefore, there was either no change in this welding wire property, or the vaporable containment on these welding wires could not be detected properly because of their specific composition.

\section{Adhesion Factors and Roughness}

In Fig. 6A, the highest adhesion factor occurs for the welding wire of manufacturer 2. The significant scattering of the values in Fig. 6B either hints to shortcomings in the measurement method or, in addition, to actual varying wire properties over the length of a welding wire spooled on a coil and varying guidance core properties. Therefore, a characterization of "a" welding wire goes along with a statistical fuzziness. However, trends and correlations are clearly recognizable using trend lines. After all, the adhesion factor increased in any case. It must be considered that the roughness of a welding wire surface - and therefore the adhesion - is not affected by the growth of the natural oxide layer directly because the natural oxide layer thicknesses are within the range of a few nanometers, whereas roughness parameters are specified in micrometers.

The statistical roughness values, depicted in Fig. 7, did not correlate with the adhesion factors. In contrast to the alignment of grooves on the surface in relation to the welding wire axis, grooves transverse to the welding wire axis governed the friction behav- 

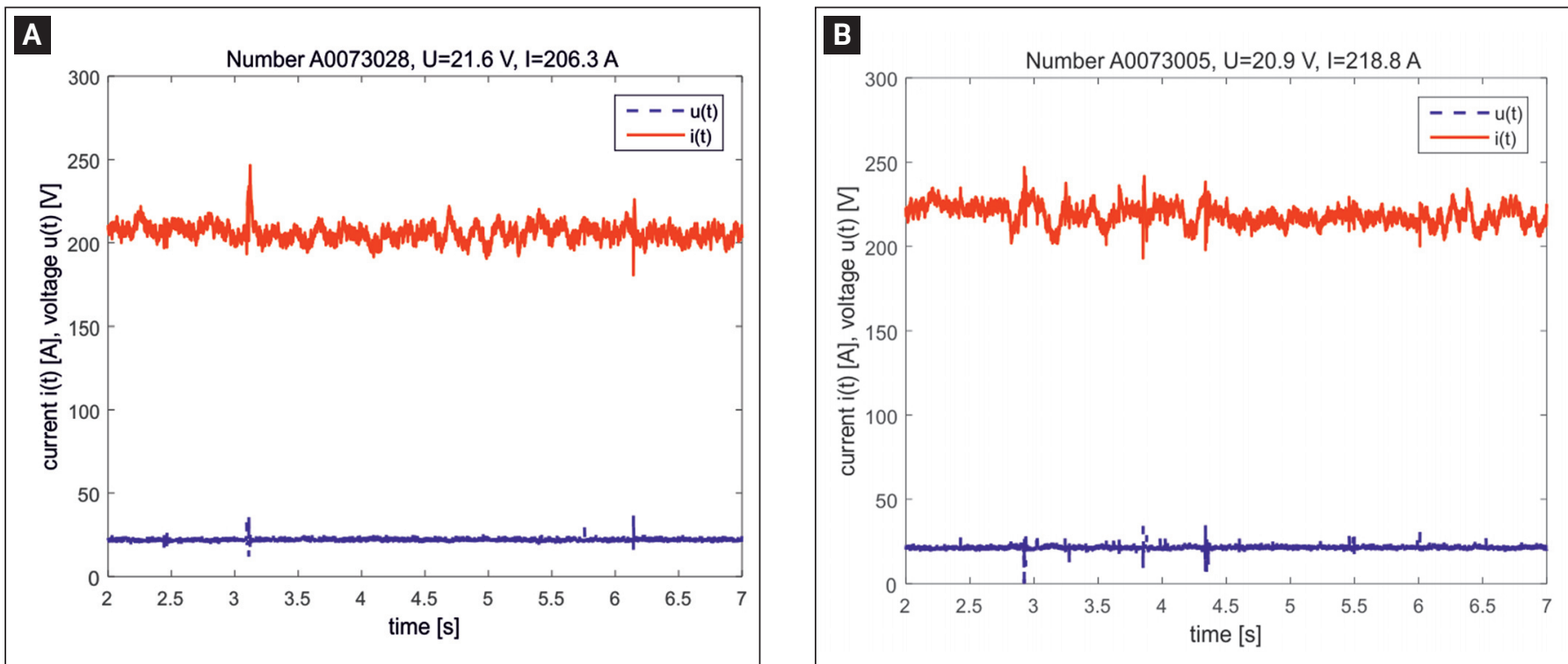

Fig. 10 - Transient process voltage $u(t)$ and current $i(t)$ using welding wires from manufacturer 1 : A - New welding wire; B - welding wire stored 295 days in a h.w. climate.

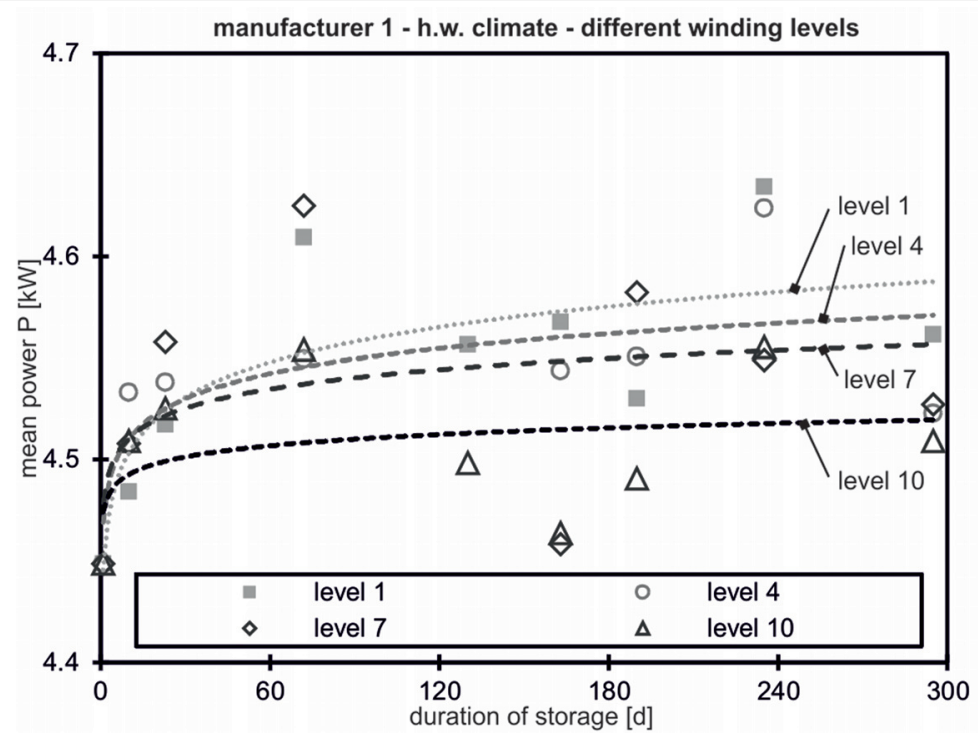

Fig. 11 - Change of the mean welding process power, which is dependent on the winding level.

ior. The natural oxide layer, grown during 112 days in a h.w. climate, did not affect the roughness values at all, as expected.

Thus, the increasing adhesion factors were suspected to succeed from changes of the antifriction agent. Furthermore, increasing the oxide layer thickness may also lead to an increasing amount of oxide particles abraded from the welding wire surface. However, since the PTFE guidance core was replaced for each measurement, this influence factor was considered to be a minor one. The changes in the adhesion factors seem to correlate with the trends in the vaporable sums of smoke (compare to Fig. 5).

\section{Hydrogen Quantity}

If it is assumed that the vaporable containments consisted mostly of an antifriction agent and contained hydrogen, a correlation between the sum of smoke, the adhesion factor, and the hydrogen quantity in Fig. 8A can be found. It may be concluded that an- tifriction agent of manufacturer 1 was nonsensitive during storage while manufacturer 2 used the least amount of the antifriction agent. Additionally, the antifriction agent of manufacturer 3 changed quickly during storage.

During this long-term research, the total hydrogen quantity decreased Fig. 8B. Prior to this result, it was expected to increase in accordance with Ref. 1, when hydrogen is absorbed by the surface layer on the aluminum welding wires.

A liberation of intercalated hydrogen from this surface layer can be taken into account, since this process is generally possible, even at temperatures well below $165^{\circ} \mathrm{C}\left(329^{\circ} \mathrm{F}\right.$ ) (Ref. 12). Simultaneously, it could also be assumed that an elevated hydrogen content of the aluminum oxide layer on a new welding wire is a possible result of the manufacturing process in the first place.

In summary, the total hydrogen quantities of the welding wires changed during almost one year of storage. Thus, no balance between absorption and possible liberation of hydrogen in and out of the aluminum oxide layer, nor evaporation of substances, unfolded.

The welding wires exposed to a h.w. climate without packaging showed a slightly faster decrease of hydrogen quantity than those stored in an ind. climate in their paperboards. Thus, 

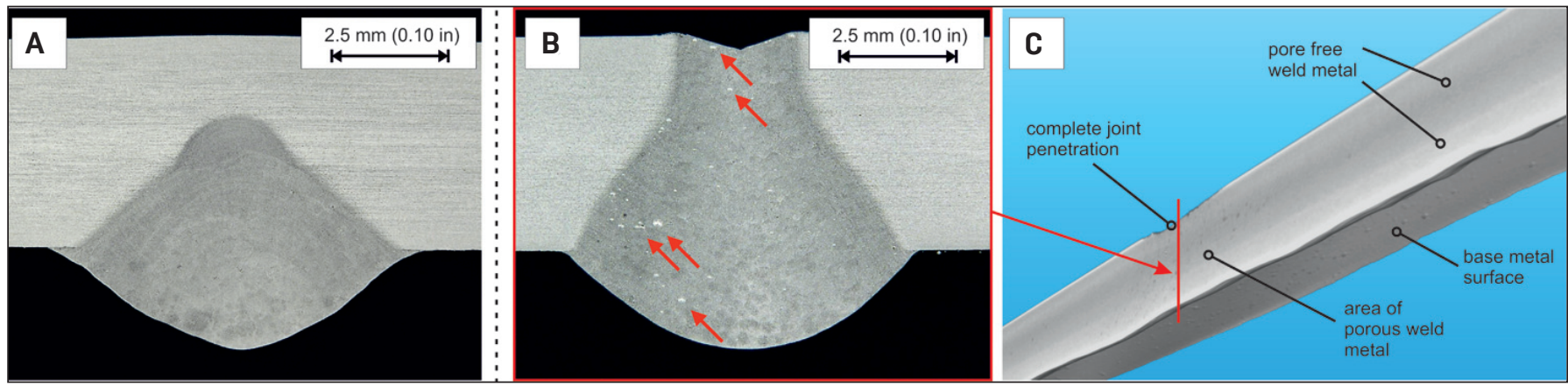

Fig. $12-A-$ Transversal cross section and logitudinal 3D microfocus CT scan: A - Transversal cross section of a weld metal produced with a new welding wire; $B$ and $C$ - Complete joint penetration area produced with a welding wire stored 234 days in a h.w. climate.

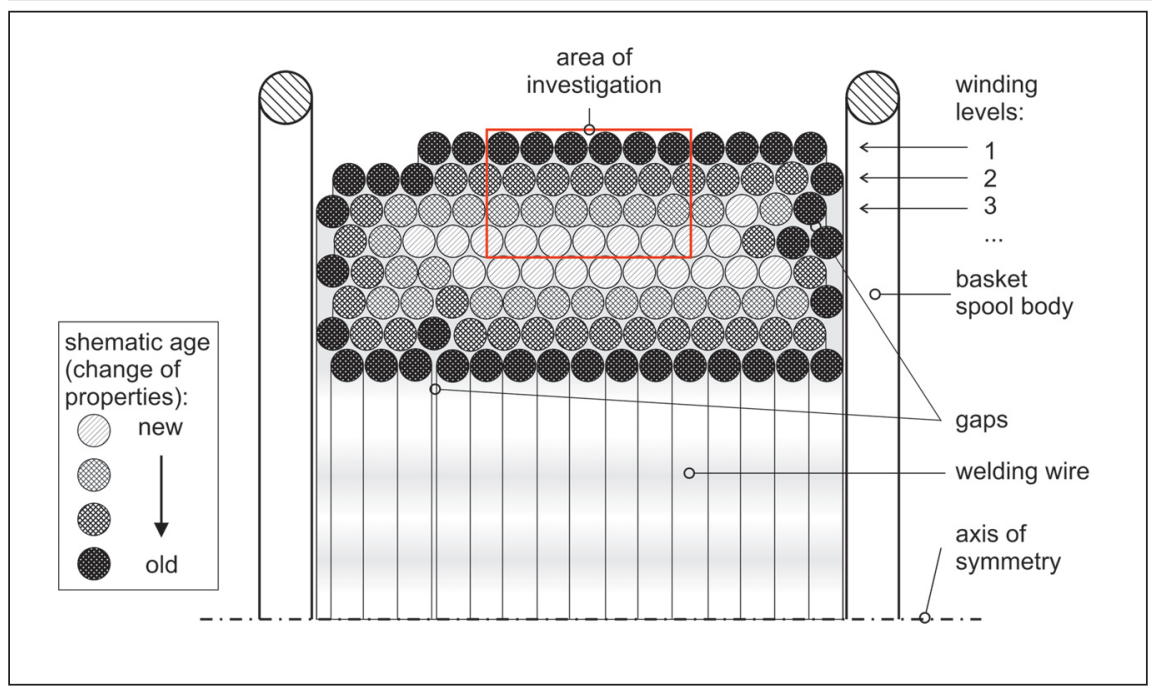

Fig. 13 - Exemplary cross section of the welding wire layers on a basket spool with schematic aging.

temperature and air exchange affected the speed of the change.

The measured decrease of the total hydrogen quantity must have been caused by evaporation of substances (e.g., antifriction and drawing agents) from the welding wire surfaces and the possible liberation of hydrogen from the oxide layer. Within the course of this research, it was not possible to resolve the ratio of these two effects on the total decrease. However, the rate of change of the hydrogen content of the welding wires from the different manufacturers, represented by the course of the trend lines, best matched the rate of change of the sums of smoke. Thus, it is assumed that the evaporation of the previously mentioned substances was of a much greater effect to welding wire properties (including the hydrogen quantity) than the change of the natural aluminum oxide layer.

\section{Electric Welding Characteristics}

The general difference of the mean power values between the three different manufacturers in Fig. 9A are supposed to be due to slightly varying welding wire diameters resulting from deviations in production. A smaller current bearing cross-section area of a welding wire will lead to an increased ohmic resistance in the electrode extension between the contact tip and the arc. Furthermore, an electrode with a small cross-section area is consumed faster, so the arc length and voltage tend to increase. To maintain a constant voltage welding process, the power source will therefore regulate the welding current to a lower level. The welding wires of manufacturer 1 , stored in a h.w. climate, exhibited a stronger difference to the initial values than those welding wires stored indoors - Fig. 9B. This suggested a stronger impairment of the more unfavorable climate to the wire properties and, in turn, to the welding process. The electric characteristics of an arc partly depends on the distance between the contact tip and the base metal surface. A considerable fluctuation of this distance would have led to a random variation instead.

During welding, the current fluctuated a bit more when using aged welding wires - Fig. 10. However, the current shifted completely to a higher level. As a result, the increase in the welding current was not derived from process disturbances. It is assumed that the change in the electric parameters was caused by a change in the electric conductivity and heat conductivity of the arc, which is affected by the metal vapor composition.

As assumed, the change in the mean power of the welding process took place more slowly the more the windings underneath were sheltered - Fig. 11. However, this welding wire property changed even at winding level ten. Considering a general dependance of the welding wire properties from the shielding by winding levels between the effect of the ambient atmosphere and the investigated windings, the actual aging state must also partly depend on the winding density. Consequently, a universal statement on how many winding levels one would have to discard to obtain unaged wire properties can hardly be phrased.

Figure 13 shows a model of the schematic aging with the change of any properties in a welding wire cross section of a basket spool. In contrast to a plastic spool, this welding wire is in contact with the ambient atmos- 
phere from the inner and outer cylindrical surfaces as well as the sidelong faces. The aging may intrude unevenly if there are gaps between the single windings or if the spool is partly sheltered from the ambient atmosphere (e.g., by its alignment during storage). For simplification, only eight winding levels are depicted, whereas a real spool of 15-kg (33.1-lb) aluminum may contain about 40 winding levels.

\section{Pore Quantity and Depth of Fusion}

Since the mean power increased with the welding wire age, the mean depth of fusion increased as well. The surface weld beads produced in this research partly reached complete joint penetration. This resulted in pore formation if hydrogen was able to intrude the weld pool from the rear side of the base metal plates. However, using aged aluminum magnesium alloy welding wires alone did not necessarily lead to a detectable pore formation.

\section{Conclusions}

The following conclusions may be obtained:

1) The accuracy of the current methods to determine welding wire properties are limited, both in quality and quantity. However, trends and correlations are clearly recognizable using trend lines.

2) After long-term storage of the aluminum magnesium alloy welding wires in a constant indoor climate and even in the unfavorable constantly humid and warm climate without any packaging, pores resulting from hydrogen of the welding wires did not occur in the weld metals, even under the tightened conditions of welding in the overhead position.

3) The change of specific welding wire properties (such as hydrogen quantity and the adhesion factor) are due to substance changes on the welding wire surfaces rather than aging of the welding wires by means of a natural oxide layer growth in a constant climate without condensation.

4) The electric welding process characteristics changed within narrow ranges, resulting in a higher process power and a higher depth of fusion.

5) The different winding diameters did not exhibit a considerable impact on the electric characteristics of the welding process.

6) The growth of the natural oxide layer did not affect the roughness characteristics on the welding wire surfaces. A scalar roughness value alone was insufficient to characterize the friction behavior, since the orientation of grooves dominated the adhesion factor.

\section{Acknowledgments}

This work was supported by the Research Association on Welding and Allied Processes of the German Welding Society and the German Federation of Industrial Research Associations (reference number $17.524 \mathrm{~N}$ ). The authors would like to express their thanks for the support.

\section{References}

1. Reisgen, U., Willms, K., and Wieland, S. 2017. The influence of storage conditions on aluminum welding wires 4043A. Welding Journal 96(6): 220-s to 227-s.

2. Vargel, C. 2004. Corrosion of Aluminium. Paris: Elsevier Science Ltd.

3. Mathers, G. 2002. The Welding of Aluminium and Its alloys. Boca Raton, Fla.: CRC Press; Cambridge, England: Woodhead Publishing.

4. N. N. 1963. The Arc Welding of Aluminium. Information Bulletin 19. London, England, Aluminium Federation.

5. Coe, F. R. 1968. The quality asses- ment of gas metal arc welding wire. Welding Journal 47(8): 355-s to 363-s.

6. Kubaschewski, O., Cibula, A., and Moore, D. C. 1970. Gases and Metals. London, New York: Iliffe; American Elsevier for the Metals and Metallurgy Trust.

7. Hansen, M. 1958. Constitution of Binary Alloys. New York: McGraw-Hill.

8. Hunter, M. S., and Fowle, P. 1956.

Natural and thermally formed oxide films on aluminum. Journal of the Electrochemical Society 103(9): 482-486.

9. Uchida, A. 1970. The Influence of Storage of Electrode Wire on the Quality of MIG-welded Joints of Aluminium Alloy. Japan Institute of Light Material Welding Paper No. 4.

10. Kammer, P. A., Randall, M. D., Monroe, R. E., and Groth, W. G. 1963. The relation of filler wire hydrogen to aluminiumweld porosity. Welding Journal 42(10): 433s to 441-s.

11. N. N. 2008. MIG welding of aluminum. Devices, Processes, Consumables. DVS bulletin 0913-2, 5, Düsseldorf, Germany, DVS-Publisher.

12. Keller, F., and Edwards, J. D. 1948. Composition and properties of the natural oxide film on aluminium. Metal Progress 54: 195-200.

13. Hatch, J. E. 1984. Aluminum: Properties and Physical Metallurgy. Metals Park, Ohio: ASM.

14. Altenpohl, D. G. 1965. Aluminum and Aluminum Alloys. Berlin, Germany: Springer.

15. Domony, A., and Lichtenberger-Bajza, E. 1961. Investigation of the formation mechanism and the properties of protective layers forming on aluminum due to different extrinsic energy ratios. Metalloberfläche 15: 134-139.

16. Roebock, A. H., and Pritchett, T. R. 1966. Corrosion inhibitors for aluminum. Materials Protection 5(7): 16-19.

17. N. N. 2004. DIN EN ISO 18273, Welding Consumables - Wire Electrodes, Wires and Rods for Welding of Aluminium and Aluminium Alloy - Classification. Berlin, Germany, Beuth.

18. N. N. 2014. Methods for the determination of the hydrogen content of the aluminum solid wires and solid rods for arc and beam welding. DVS bulletin 0947, 1, Düsseldorf, Germany, DVS-Publisher. 